\title{
CMA hosts first town hall on health care transformation
}

$\mathrm{W}$ hile it's been said Canadians suffer under a "delusion" that they have one of the best public health care systems in the world, there was little evidence of such a conceit among the frustrated patients and health professionals who attended the first in a series of town hall meetings on health care transformation hosted by the Canadian Medical Association.

Complaining of "inordinately long" wait times, "gross inequities" in access to treatment and "vast" waste within the system, participants at the meeting in Halifax, Nova Scotia urged the creation of a more "proactive" system that would emphasize prevention, while curbing unnecessary procedures and visits to the emergency room.

"Inefficiency in health care is harming people, and indeed, in some cases, literally killing them," said Andrew Coyne, national editor of Maclean's and a panelist at the meeting. "If we want to save the system we have with universal accessibility, we have a moral imperative to look at changes to preserve that system."

Both panelists and participants suggested that bolstering preventive care was a means of improving the overall health of Canadians and reducing strain on the acute care system.

"We need to focus more on some of the health quality improvement activities as opposed to consuming and putting more and more dollars towards expensive health care," said panelist Dr. John Ross, provincial advisor of emergency care for Nova Scotia.

One such activity would be to define the heaviest users of the health care system and target early treatment and risk prevention programs to address their health needs, Ross said. "In Ontario, $1 \%$ of the population consumes $49 \%$ of the hospital and home care costs. ... Who are these people, where do they live, what kind of disease processes do they have and are there things we could do to manage them better to prevent emergency

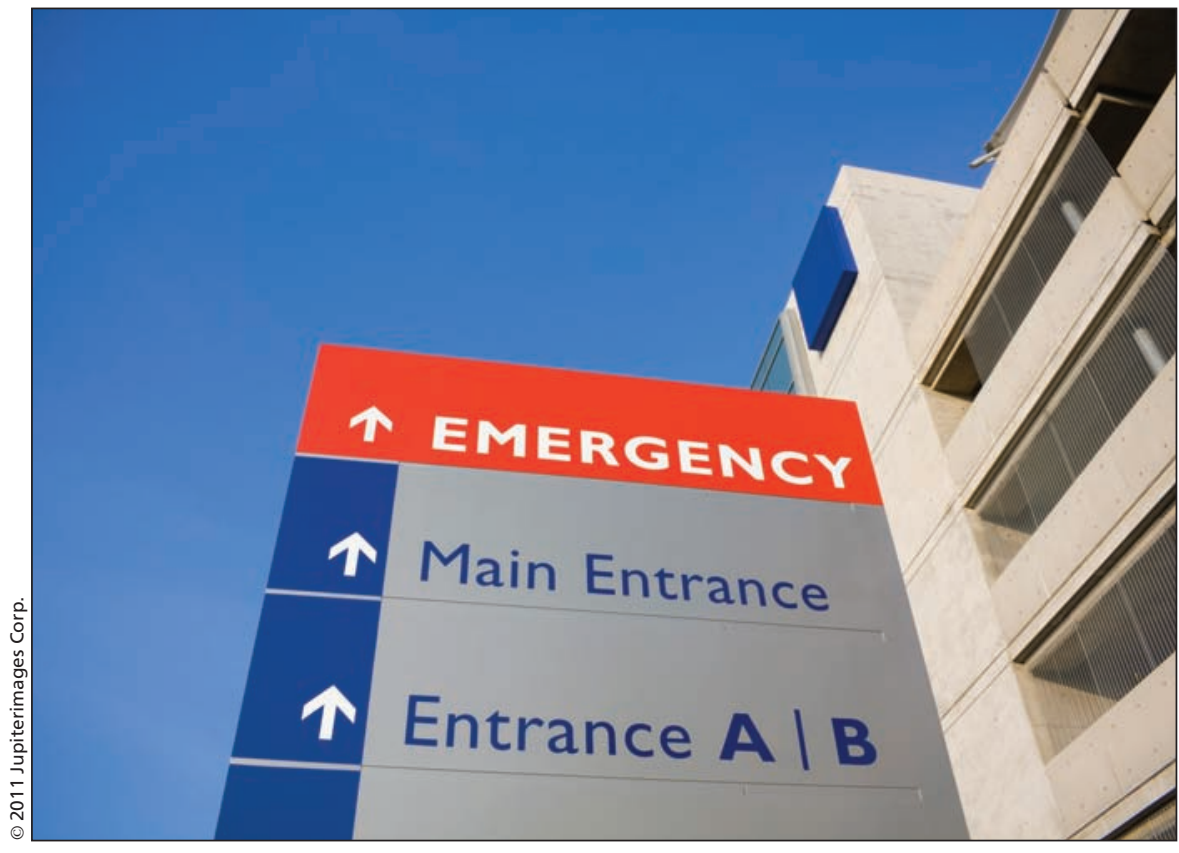

Reducing visits to emergency rooms by increasing support for long-term, home and palliative care programs were among measures urged by participants to a forum on health care transformation hosted by the Canadian Medical Association in Halifax, Nova Scotia.

department visits, hospital admissions, diagnostic testing and so on?"

A national poverty reduction strategy could also serve to reduce the burden on the health care system, said Coyne, as people living in poverty "typically lead an unhealthy lifestyle and are also great health care cost drivers."

"We can't be taking a victim blaming approach to individuals - saying why aren't you healthier or why aren't you exercising? - if we haven't created a social environment that supports those healthier behaviours," added panelist Maureen Summers, CEO of the Canadian Cancer Society Nova Scotia division. "All Canadians must have access to the medical care and treatment they require without financial hardship."

Both through taxes and directly outof-pocket for drugs or other health needs, Canadians are the fifth highest per capita spenders on health care among 32 Organisation for Economic Co-operation and Development nations.

One of the big "whammies" that hits many Canadians after receiving a can- cer diagnosis is the "constant worrying about finances, about whether you can afford to pay for the drugs you need or whether to choose [to] not buy them because you need to put food on the table for your children," said Summers.

A national pharmaceutical strategy to provide Canadians with treatments they require would not only reduce stress on patients, but also on the system, she added, because many cancer patients would opt to take chemotherapy drugs at home, rather than go back and forth to the hospital.

A system that acknowledges and addresses some of the social determinants of health and collaborates on risk prevention with other provincial departments, such as education, would considerably ease the strain on front line acute care workers, one physician told the gathering. "When I go into work, I'm not only a doctor. I'm a fireman. I have to put out fires where it's chronic disease management, mental health issues, trying to find drugs for someone who doesn't have insulin and needs it in two 
days, or some sort of social services issue that I'm not trained to do."

Coyne argued that the problems are confounded by a fee-for-service payment model that de facto provides a financial incentive for physicians to conduct unnecessary procedures and testing. "We can tell people they should do this or that but ultimately it comes down to incentives. People do things not because they're right but because there's some sort of monetary penalty or reward to it."

Although user fees have been suggested as an antidote to such over-treatment, Coyne was skeptical that most patients would feel "empowered to contradict" a course of action prescribed by their doctor.

Conversely, some doctors feel compelled to provide any and all treatments that a patient requests, even when medical intervention may not significantly extend or improve that person's life, one cardiac surgeon told the forum. "We have to start making some difficult rationalizations around who we're going to treat ... It just continues to add cost and complexity in the system. As a health care provider, I'm bound by the Hippocratic oath to provide care to the patient population that comes to me. We don't say at 85 you've lived well and there are some criteria by which I'm going to do a double-valve replacement on you. But we should judge whether or not the potential years of life saved can be justified by that treatment."

Ross said many patients may not belong in hospital at end of life, and would be better served by increased funding and support for long-term care, home care and palliative care programs. "I know a number of quite demented people right now who are getting various types of tests done, dialysis and various types of interventions. When you look at where this effort is going, what the end point is - is that really a valuable way to spend that diagnostic testing and dying person's time or is there an option to say maybe we should consider palliation in this particular case and do something else with those valuable dollars. We do need to make some difficult decisions."

Patients also have a responsibility to advocate for their own health care and their health care system, said CMA president Dr. Jeff Turnbull. "We accept a health care system that is not deliver- ing value for money. ... Our elected leadership will not lead. They will follow. You have to give them the imperative to change."

The town hall meetings are part of a broader public consultation that the CMA launched in 2010 to spark an "adult conversation" on updating and expanding the Canada Health Act (www.cmaj.ca/cgi/doi/10.1503/cmaj.10 9-3333).

Yet, despite consensus on the "real need for action" in the first of the town hall meetings, there appeared to be little appetite for reopening the federal legislation.

One participant called it a "dangerous" move, which would likely become highly political and an "open target for professional agendas and turf wars that exist in our system."

"My worry is that we'll make such a mess of the design of this that we'll take on enormous additional unfunded liabilities," said Coyne. But "if we wait for the big national vision from whoever's in power, we're going to be waiting a long time." - Lauren Vogel, CMAJ

CMAJ 2011. DOI:10.1503/cmaj.109-3797 